\title{
PINTURA EM LECOQ: uma poética corporal
}

\author{
PINTURA EN LECOQ: \\ una poética corporal
}

\author{
PAINTING IN LECOQ: \\ a body poetics
}

\author{
Cláudia Müller Sachs ${ }^{1}$
}

\begin{abstract}
RESUMO
O presente artigo aborda um conjunto de práticas corporais provenientes da pedagogia de Jacques Lecoq (1921-1999) relacionadas à arte da pintura. Além da experiência própria vivida em sua escola em 1992/93 e 2015, trazemos aqui considerações baseadas no curso de pesquisa e extensão realizado na Universidade Federal do Rio Grande do Sul entre 2017 e 2018, intitulado "Pintura em Lecoq: composição a partir do movimento no espaço" enfatizando o modo como essas práticas contribuem para a imaginação do ator. Descrevemos algumas das práticas na íntegra como modo de divulgar esse conhecimento e de tentar abarcar a extensão filosófica dessa pedagogia por meio da noção de Fundo poético comum.

PALAVRAS-CHAVE: fundo poético comum; movimento, Lecoq, atuação teatral, corpo, pintura.
\end{abstract}

\section{RESUMEN}

El presente artículo aborda un conjunto de prácticas corporales provenientes de la pedagogía de Jacques Lecoq (1921-1999) relacionadas con el arte de la pintura. Además de la experiencia propia vivida en su escuela en 1992/93 y 2015, traemos aquí consideraciones basadas en el curso de investigación y extensión realizado en la Universidad Federal de Rio Grande do Sul entre 2017 y 2018, titulado "Pintura en Lecoq: composición a partir del movimiento en el espacio "enfatizando el modo en que estas prácticas contribuyen a la imaginación del actor. Describimos algunas de las prácticas en su totalidad como modo de divulgar ese conocimiento y de intentar abarcar la extensión filosófica de esa pedagogía por medio de la noción de Fondo poético común.

PALABRAS CLAVE: fondo poético común, movimiento, Lecoq, actuación, cuerpo; pintura.

\footnotetext{
1 Professora Adjunto A de práticas corporais no Departamento de Arte Dramática da Universidade Federal do Rio Grande do Sul (UFRGS). Doutorado (2013) e Mestrado (2004) em TEATRO na Universidade do Estado de Santa Catarina/UDESC. Trabalha como atriz, diretora, preparadora corporal e professora de teatro e dança, com ênfase em interpretação, movimento corporal, improvisação e preparação de ator.
} 


\begin{abstract}
This article deals with a set of body practices from the pedagogy of Jacques Lecoq (1921-1999) related to the art of painting. In addition to my own experience at his school in 1992/93 and 2015, we present here considerations based on the research and extension course held at the Federal University of Rio Grande do Sul between 2017 and 2018, entitled "Painting in Lecoq: composition from the movement in space "emphasizing how these practices contribute to the actor's imagination. We describe some of the practices in full as a way of disseminating this knowledge and of trying to embrace the philosophical extension of this pedagogy through the notion of the universal poetic awareness.
\end{abstract}

KEYWORDS: universal poetic, awareness, movement,Lecoq, acting, body, painting.

$\mathrm{O}$ artista dedica sua vida ao que ainda não é real, mas que reside dentro da matéria.

(Aristóteles).

O presente artigo aborda um conjunto de práticas corporais provenientes da pedagogia de Jacques Lecoq (1921-1999) relacionadas à arte da pintura. Em sua escola esse tema faz parte do tema por ele intitulado "abordagem pelas artes". Essa abordagem abarca a arte da pintura, da música e da poesia como referências para o trabalho de criação do ator, sempre buscando perceber a dinâmica interna dessas manifestações para transformá-las em movimentos do corpo, tanto individual como coletivo. Esse conjunto de práticas serve para o desenvolvimento do trabalho do ator trabalhando objetivamente com princípios do movimento corporal e do jogo teatral, com práticas organizadas de maneira evolutiva, além de ampliar a capacidade perceptiva de tudo o que nos cerca.

Além da experiência própria vivida em sua escola em 1992/93 e 2015, trazemos aqui considerações baseadas no curso de pesquisa e extensão na Universidade Federal do Rio Grande do Sul entre 2017 e 2018, intitulado Pintura em Lecoq: composição a partir do movimento no espaço. O projeto, que deve ter seguimento em 2019, propõe a formação de um núcleo de experimentação voltado para a criação cênica a partir do movimento enfatizando o corpo como suporte para processos interdisciplinares entre as artes. 
O tema da "abordagem pelas artes" abarca uma dimensão abstrata subjacente ao trabalho corporal por ele desenvolvido, ancorado na noção de 'Fundo Poético Comum'. Para Lecoq, tal noção trata-se de uma dimensão abstrata feita de espaços, de cores, de luzes, de matérias, de sons, que se encontram depositadas em cada um de nós a partir de nossas diversas experiências, que constituem um fundo comum a partir do qual surgem os impulsos e desejos de criação. O processo pedagógico toma a observação da natureza como base e a transferência de suas dinâmicas para o corpo e para a cena como modos de criação. O trabalho envolve análise do movimento, improvisações e criação de cenas, visando enriquecer a capacidade expressiva do ator com possibilidades de movimento que possam contribuir para a eliminação de vícios de atuação e de automatismos impregnados, no intuito de facilitar o acesso a sua própria poética.

A ideia de 'Fundo Poético Comum' foi um dos aspectos da pedagogia de Lecoq que mais me chamou atenção desde que cursei sua Escola em Paris (1992/93), que identifico como o diferencial em seu trabalho e que lhe confere uma dimensão atemporal, para além de tendências passageiras. Em minha tese de doutorado tomei essa noção como eixo central para estudar a questão da imaginação do ator, analisando a possível contribuição destas práticas de Lecoq para o desenvolvimento dessa competência, o que me levou à confirmação de sua efetividade e relevância até hoje.

Em minha tese de doutorado, intitulada "A imaginação é um músculo: a contribuição de Jacques Lecoq para o jogo do ator", realizei uma reflexão sobre a imaginação na prática pedagógica de Jacque Lecoq para os estudos dos processos formativos e criativos do ator. A partir dessa afirmação de uma de suas célebres ex-alunas, Ariane Mnoushkine, de que "a imaginação é um músculo", abordei a imaginação tanto como algo que devemos desenvolver mentalmente, como enquanto trabalho físico que exige a experiência prática. A pesquisa teve por objetivo uma melhor compreensão de minha experiência como atriz, diretora, preparadora corporal e professora por meio da análise conceitual de aspectos dessa pedagogia. Assim, desenvolvi alguns experimentos práticos, como cursos, oficinas e direção de 
espetáculos para melhor verificar essa relação com a imaginação, realizando entrevistas com os participantes e registros em vídeo e fotografias.

Considerando a imaginação como competência fundamental no trabalho do ator, encontrei nessa pedagogia alternativas concretas para seu desenvolvimento, amparada por técnicas corporais que levam ao despertar perceptivo de si ancorada na observação das mais diversas manifestações da natureza. Assim, as técnicas propostas por Lecoq mantêm-se como tema de minhas investigações e de minha prática artística e pedagógica, acreditando na riqueza de seu pensamento sobre teatro, arte e vida.

Minha pesquisa aponta a noção de 'Fundo Poético Comum' como a visão fundamental nessa pedagogia, servindo como inspiração para a imaginação do ator na medida em que passa a perceber e associar as diversas dinâmicas da vida a seus movimentos. Refere-se ao caráter universal presente em todo e qualquer fenômeno da vida, uma linguagem que está presente tanto nas diferentes manifestações da natureza como em nossos corpos. Sugere que todos os humanos compartilham uma sensibilidade a essa dimensão abstrata feita de formas, luzes, cores, matérias e sons. Evidenciando uma tendência essencialista, Lecoq interessava-se pela essência imutável de qualquer coisa, que chamava de "poética das permanências", a busca daquilo que é permanente, que a diferencia de qualquer outra (Lecoq, 1999, p.32). O professor costumava usar como exemplo as árvores que, embora existam em inúmeras espécies, tipos, tamanhos, cores, há algo que lhes é essencial, que vai diferenciá-las de qualquer outra coisa, que faz com que as reconheçamos como árvores, vivas ou mortas. Sua identidade permanente, independentemente da cultura ou de crenças a ela relacionadas. Da mesma maneira, as cores, luzes e formas que, ainda que carreguem diferentes significados culturais atribuídos a cada uma, há no fundo algo que faz com que as reconheçamos como tal, e que possuem uma dinâmica particular. Nesse sentido, seu pensamento aproxima-se do conceito de mimesis de Aristóteles, que se refere ao caráter substancial subjacente a todas as artes. 
Alinhada a esse pensamento, enfocamos o aspecto técnico e poético, o saber prático que o ator deve desenvolver. Como aponta Dantas (1999, p.30), a técnica transforma a matéria, está ligada à ideia de poiesis, que significa criar, fabricar, executar, compor, construir, produzir, fazer, obrar, agir com eficácia, produzindo um resultado. Assim, é desejável que o ator desenvolva habilidades que o levem ao saber prático, o saber criativo, o saber poético. $\mathrm{O}$ trabalho da imaginação relacionado ao 'Fundo Poético Comum' é tomado, então, como modo de disponibilização e de abertura para a criação. Trabalha-se com o distanciamento do naturalismo, o corpo poético não cotidiano.

A evolução da pedagogia de Lecoq dá-se através de temas que são trabalhados de maneira acumulativa, baseados em certos princípios, chamadas de "leis do movimento"2. Diretamente ligados à natureza, à vida, ao cotidiano e à interação entre todas as coisas, os temas abordados ao longo do primeiro ano da escola são basicamente os seguintes: os elementos da natureza; os cataclismos; as matérias; as cores; as luzes; as artes da pintura, da poesia e da música; as palavras; os animais; as paixões. A cada novo tema introduzido, os alunos partem para a observação em diferentes locais onde possam entrar em contato com ele. De volta à sala de trabalho, trazem sua experiência e, aliadas às técnicas corporais desenvolvidas nas aulas de análise do movimento, procuram aplicar ao jogo dramático aquela dinâmica, o pulsar daquele tema através de seus corpos.

A ideia central da experimentação com os diversos temas é encontrar a dinâmica interna de cada elemento, o 'Fundo Poético Comum' a todas as manifestações da natureza e a cada indivíduo. Quando trabalhamos as cores, por exemplo, busca-se encontrar em nossos corpos o 'amarelo de todos amarelos' ou o 'vermelho de todos os vermelhos', independentemente de valores ou associações simbólicas a elas atribuídas. São fenômenos da natureza que se mostram para todos os humanos da mesma maneira, enquanto percepção. O 'Fundo Poético Comum' refere-se, portanto, àquilo que está além da leitura simbólica, àquilo que é física, e que sabemos que

\footnotetext{
2 Lecoq 1997, p.100
} 
tem uma dinâmica específica na maneira como se organizam suas ondas de energia, suas moléculas.

No presente artigo enfoco o trabalho com a pintura. Para tanto, iniciamos com exercícios que envolvem o trabalho com os elementos e as matérias, a percepção do espaço, da luz e das cores, com improvisações que visam despertar para a dinâmica intrínseca nessas diferentes manifestações da natureza, procurando reproduzi-las e jogar com elas sem um caráter psicológico. Tomando obras de alguns pintores como referência, estudamos as relações compositivas das linhas, manchas, cores e é esse material que trazemos para o corpo e para a cena.

Em minha pesquisa, além das práticas aprendidas na escola de Lecoq, utilizo outras de acordo com necessidades específicas do grupo. Essas propostas de improvisação com a arquitetura dos espaços, as cores, as luzes, as texturas, etc., são de difícil execução dado o caráter aparentemente abstrato e a necessidade de o indivíduo abrir-se para a observação desses aspectos no ambiente, para além de sua memória. A sutileza dessa abordagem, entretanto, promove uma rede de imagens que vai tomando forma, na cena e na imaginação, acarretando no alargamento criativo a partir das possibilidades que ali surgem, sempre baseadas na natureza, naquilo que existe, visível ou invisível, o que se apresenta como um diferencial dessa visão de teatro.

Os exercícios são propostos com instruções objetivas, sucintas, de modo que o indivíduo desenvolva a disponibilidade para experimentar, arriscar e criar. Nesse sentido, me alinho à maneira de entender as questões sobre a ação no trabalho atoral apontadas por Nunes (2009, p.130) que considera que "para adquirir um conhecimento é preciso exercer a atividade correspondente, ou seja, só aprendemos fazendo." Partimos do movimento, de dinâmicas, de deslocamentos e ritmos, das relações sinestésicas que registram modos de estar "aqui e agora" trabalhando, assim, a presença cênica. Ao sairmos da sala de trabalho e nos depararmos com a rua, as pessoas, os sons, os ritmos, as luzes, etc., vamos instalando uma maneira de ver e de observar constante, resultando num aprendizado do olhar, numa 
ampliação da percepção e de alternativas para nossos próprios movimentos. Uma "escola do olhar", como afirmava o professor.

Com a observação da natureza e a memória sinestésica gerada pela prática a imaginação vai sendo trabalhada, vamos corporificando e presentificando essas informações. Pode-se perceber nesse tipo de abordagem a herança de Jacques Copeau (1879-1949) e de todo um pensamento do início do século XX voltado para as práticas corporais em oposição ao psicologismo que imperava até então. As diversas experiências formativas surgidas nesse século, entre estúdios, laboratórios e escolas na Europa e nos Estados Unidos, embora baseadas em desejos estéticos e políticos diferentes, compartilhavam de uma ampla reflexão sobre o processo criativo e a aprendizagem do ofício do ator em oposição à pedagogia conservadora e às convenções. Também o teatro francês, principalmente a partir de Copeau, inclina-se para essa reeducação do ator e, na metade do século (1956), imbuído deste mesmo espírito, surgirá a escola de Jacques Lecoq, herdeiro de muitos dos princípios lá desenvolvidos ${ }^{4}$.

Para abordar o tema da Pintura, iniciamos com a prática que envolve os elementos - água, ar, fogo e terra -, por meio de uma "viagem elemental", termo usado por Lecoq, mas que eu venho adaptando e aproximando do imaginário brasileiro. Assim, iniciamos de olhos fechados, entrando em contato com seu equilíbrio, atenção ao seu apoio no solo, como uma garrafa que boia em alto mar. A partir daí vamos nos conectando com a dinâmica dessa imensa massa de água salgada e profunda que nos cerca, diluindo a garrafa e tornando-se esse elemento, que progressivamente avança até chegar à praia e, com a influência do vento, estourar em ondas, lamber a areia, e recuar. Pouco a pouco vai tornando-se a calma e doce água de um lago. A partir dos pés vamos entrando em contato com a lama do fundo desse lago, e vamos nos deixando preencher com ele vagarosamente experimentando essa textura plástica do lodo. Com a presença intensa do sol o lodo vai secando a água sob a forma de evaporação, que consequentemente

\footnotetext{
${ }^{3}$ Lecoq (1997, p.31)

${ }^{4}$ Sobre as relações entre Copeau e Lecoq, ver SACHS, 2004; FREIXE, 2014; LORELLE, 2007.
} 
torna-se terra seca, e a partir dos pés, surgem raízes que penetram o solo, estabilizam fortemente o corpo, que agora torna-se árvore. Um vento surge, move os galhos e as folhas, aumenta sua intensidade cada vez mais, aproximando-se de uma ventania de temporal. Decorrente, uma folha desprende-se da árvore, que voa solta à mercê das rajadas, somos a folha, somos o vento. Em um ponto, a folha atravessa uma faísca pega fogo e queima em grandes labaredas, um grande incêndio, que depois vai acalmando como uma fogueira que vai se extinguindo, queima a madeira, que progressivamente quebra-se e torna-se cinzas e pó. Todos terminam deitados no chão, de barriga pra cima, relaxados. Finalizando o exercício, retoma-se mentalmente todo o trajeto e diz-se em voz alta uma palavra que sintetiza esta sensação.

Costumo conduzir essa vivência chamando atenção para as imagens que surgem, assim como as diferentes qualidades de tensão do corpo, para observarem as linhas e os ritmos com que se deslocam e aquilo que esses eventos provocam no espaço, sutilezas desses diferentes estados. Suscito algumas frases curtas nos diferentes momentos, de modo que percebam o quanto o estado do corpo modifica a voz, e por vezes pergunto "quem poderia ser essa figura?". Costumo alertar os alunos-atores para trabalharem com os olhos abertos, pois não se trata de terapia, mas de exercícios técnicos que demandam atenção e consciência para com seu próprio corpo e dos colegas ao redor. Perceber também o efeito desses movimentos enquanto grupo. Interessante perceber que esse exercício é uma herança da escola de Copeau, perpetuada por vários de seus seguidores, são exercícios extremamente comuns em escolas de formação de atores. $\mathrm{O}$ diferencial está na ênfase dessa busca da dinâmica interna das manifestações da natureza.

Dos elementos, passamos para as matérias (ou materiais), ou seja, experimentar as infinitas combinações dos elementos constituem as coisas, sejam elas duras, elásticas, pastosas, gasosas, gosmentas, flexíveis, enfim, trazer para seu corpo essas qualidades de tudo o que existe na natureza. A matéria vista de dentro: o corpo é a matéria que pode ser manipulada ou não, mas ela mesma não manipula visto que é passiva, como um chicle na 
boca sente os dentes, a língua e torna-se bola. Observamos como cada matéria se comporta, suas especificidades, que vão contatar com aquilo que é comum a todas, e aí tocamos o cerne da visão de Lecoq de 'Fundo Poético Comum'.

Juntando dois ou mais elementos, trabalhamos, por exemplo, com a ideia de uma pasta de dente, inicialmente pressionada no interior do tubo, fechando o corpo o máximo possível. Então o canal é aberto, esparramando o creme dental. Em seguida, é jogado um balde de água para limpar a pasta grudada ao chão. Após vários jatos, as "pastas de dente" se aglomeraram ao fundo da sala, a água presente é evaporada, e transformamo-nos em moléculas de ar. Observamos como as moléculas se relacionavam entre si no espaço para compor o ar todo da sala. As moléculas suspensas de ar começam a se condensar e todos agrupam-se ao meio da sala, e somos água dentro de uma panela efervescente. Em seguida é adicionado uma mistura em pó para pudim, que é mexida e com o desligar do fogo, esfria-se e tornando-se gelatina. Andamos pelo espaço nesta qualidade gelatinosa. Finalmente, observamos uma gelatina de brinquedo para melhor compreender as suas qualidades. Neste exercício, é interessante notar as transformações que o corpo adquire através da imaginação. Os estímulos são conduzidos de modo que cada aluno-ator busque imaginar e expressar fisicamente sua ideia dos elementos, sua onda, sua árvore. Assim, há diferentes formas de manifestação dado o repertório e identidade de cada um a partir da imaginação materializada. É um trabalho autônomo do ator e seu processo de criação.

A partir as matérias passamos a trabalhar as cores, para depois chegarmos à pintura propriamente dita. A ideia parte da busca em perceber a dinâmica das cores, o espaço que usam, o tempo que duram, se ela se move no nível alto ou no baixo, qual a intensidade de seus movimentos, se tendem a puxar ou empurrar. Normalmente trabalha-se com as cores do arco-íris: vermelho, laranja, amarelo, verde, azul, índigo, violeta. Num primeiro momento, o grande grupo trabalha em conjunto, ainda que individualmente, procurando mover-se da maneira com a dinâmica de cada cor. 
Aqui gosto de conduzir a improvisação também como uma viagem, uma vivência em que passamos por diferentes qualidades e estados psicofísicos. Imaginamo-nos em um ponto escuro, em um buraco negro, com o corpo fechado, o menor possível, um ponto escuro. Um raio de luz emerge da escuridão, lentamente aumenta de intensidade e começa a tomar conta do espaço. O corpo vai se abrindo até portar-se de pé. Em posição ereta, imagina-se a luz invadindo o espaço, permeando nossos corpos, um grande sol de muita intensidade, como o do meio dia, e então a luz transforma-se em amarelo, entramos na dinâmica dessa cor. A seguir, um pingo de vermelho mistura-se e cria o laranja. Então o amarelo se vai se dissipando e fica somente o vermelho. Um pingo de azul invade o vermelho, tornando-se roxo, depois o vermelho sai, permanecendo somente o azul. Experimentamos diferentes azuis, bem claro, marinho, Royal, e qual é o azul de todos os azuis? Lentamente, amarelo é acrescentado a esse azul e transforma-se em verde. Adiciona-se vermelho e do azul vamos ao marrom. Esta cor costuma trazer maior peso, movimentos mais lentos e densos, remetendo a lama e barro, lodo, por exemplo. Por fim, um pingo preto e nos transformamos nessa cor, voltando ao início da viagem. Depois realizamos o processo inverso, passando por todas as cores novamente, até voltarmos a ser luz novamente: dizem que somos todos luz, gosto de dizer ao final.

Num segundo momento, trabalhamos individualmente, cinco pessoas ficam em cena, experimentam uma dada cor, depois um por um as demonstra e procuramos detectar onde parece mais preciso, leplus juste, como dizia Lecoq. O mais impressionante é que podemos realmente perceber em quem identificamos melhor uma dada cor, ou, pelo menos, as cores que não são. Por exemplo, o amarelo tem uma dinâmica mais rápida, mais luminosa, mais aberta, diferente de alguém que se move com ritmos lentos ou com o corpo encurvado, fechado. Pode-se questionar se os tamanhos são senso comum, ou se somos induzidos a encontrar esse padrão que já é fruto da pesquisa anterior de Lecoq que as entendeu assim. De qualquer maneira, faz sentido aquilo que é proposto, é uma aproximação, não uma verdade inquestionável, que serve para fins pedagógicos, para que se possa 
visualizar esses espaços e assim trazer tais qualidades para o seu trabalho. Interessante atentar para a separação do simbólico, da semiótica, do representativo, do cultural, como o branco significar a paz, por exemplo. Aqui trata-se de uma busca daquilo que é essencial para que seja a tal cor, independentemente do que ela possa significar ou despertar emocionalmente. Encontrar aquilo que é permanente nesta manifestação da natureza, para além de qualquer simbolismo a ela associada, algo que Lecoq se referia como a "poética das permanências". Para o trabalho do ator, serve para que ele possa se desvencilhar de clichês ou utilizar deles para ultrapassá-los, pesquisar algo que aciona a imaginação, induzindo a uma busca pessoal do próprio do ator.

Com esses corpos despertados para os elementos, as matérias, as cores, as texturas, entramos no trabalho da pintura em si. Na abordagem de Lecoq prioriza-se a leitura de quadros enquanto composição pictórica, com suas linhas, manchas, pontos de conversão do olhar. Na escola de Lecoq, em Paris, temos como tarefa de casa observar telas em museus e bibliotecas. Aqui no Brasil, costumo levar livros com ilustrações para a sala de trabalho. Iniciamos com pintores mais conhecidos, como Miró, Chagall, Caravaggio, Kandinski, Bacon, por exemplo, e peço que os alunos-atores tragam alguns de seu interesse também.

Iniciamos contemplando o quadro (a gravura no livro) durante um tempo, conduzindo a observação chamando a atenção para as linhas, os volumes de cores, a luz, os contrastes, as tensões entre as formas e as cores, o equilíbrio e desequilíbrio elas, o trajeto do olhar. Perceber o modo como nosso olhar percorre a pintura, para onde olha-se em primeiro lugar, e em seguida, e para onde retorna o olhar, qual a leitura que o pintor propõe. Observar a matéria, o ritmo das pinceladas desse pintor, que é diferente em cada artista.

Em grupos de cinco ou seis pessoas experimentamos mostrar o quadro. Tomamos alguns minutos para nos organizarmos e em seguida mostramos o quadro em grupo, com três trocas de composições que acompanhem a dinâmica dessa obra. Normalmente inicia-se com uma 
imagem que seria a primeira impressão do quadro e logo passa-se para outras imagens seguindo a dinâmica que se acredita ser mais justa para causar a sensação do todo da tela. São enfatizadas as transições, o não movermos todos juntos para valorizar determinadas instâncias do quadro, assim como a dinâmica do corpo ao mover-se que seguirá tal ou qual matéria e cor, assim como a composição com os corpos dos colegas, o espaço que utiliza, as linhas ali presentes. Enfim, os diversos aspectos que haviam sido anteriormente trabalhados aqui fazem sentido, são o esteio que temos para amparar a improvisação, agora já no campo da criação embora ainda com regras delimitantes.

Assistimos uns aos outros e vamos procurando identificar as cores, as formas, as tensões, os ritmos, as soluções que cada um encontra para transpor determinado aspecto. No caso desse quadro acima, em especial, surgiam questões sobre como mostrar esse movimento da água que sobre em oposição ao barco que desce, a tensão em relação às pessoas na água, as linhas propostas pelas velas e a quebra que a luz aporta para a estrutura do quadro. São questões de observação, identificação, transposição. Ao observarmos os trabalhos dos diversos grupos podemos perceber as diferentes maneiras para alcançar o objetivo. Mesmo quando não se consegue nitidamente ver o quadro de onde partiram, surgem imagens do grupo ricas, curiosas, matéria bruta para construir cenas. Ao observar o trabalho dos colegas, pode-se enxergar situações, atmosferas, conflitos, estados dos atores e do grupo de prontidão e entrega, de jogarem-se num mundo abstrato com a concretude de seus corpos. Ao seguirmos o trabalho vamos em busca do movimento que essa imagem propõe, com suas formas, cores, textura, composição. Não basta uma imagem reproduzida, mas é uma série delas para expressar o movimento que ela traz, levando em conta sua emanação: intensidade, teor, a tensão entre as cores, as formas, umas em relação às outras e em relação à moldura, a composição, a pressão do pincel que denota o ritmo das pinceladas.

Em nosso grupo de pesquisa e extensão na UFRGS, depois de alguns experimentos com diferentes pintores, trabalhamos mais profundamente 
com o pintor irlandês Francis Bacon (1909-1992), inicialmente a partir da pintura Étude d’aprèsleportraitdu pape Innocent X de Velázquez (1953).

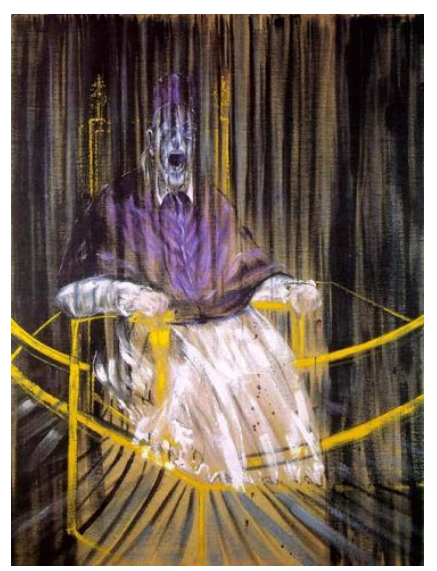

Figura 1: Study after Velázquez's Portrait of Pope Innocent X, Francis Bacon, $1953^{5}$

Para entrar no universo do Bacon, discutimos e refletimos sobre sua vida e obra e sobre esse quadro específico, chamando atenção para as cores, formas, contrastes, linhas e impressões subjetivas. Identificar as associações entre as qualidades que podem ser trazidas para a cena, como por exemplo, o derretimento que parece ser instaurado, a fantasmagoria, um certo horror e desespero que nos pareceu. Assim como dos encontros anteriores, trabalhamos com três posições estáticas, as transições entre eles e inserimos um looping, ou seja, uma volta à composição inicial, o que passou a constituir uma cena capaz de ser repetida. A partir daí, experimentamos diferentes ritmos e densidades para essa composição, inclusive com diferentes trilhas sonoras, o que resultava numa diversidade de material bruto para futuras cenas.

Ao final do semestre (julho de 2017) fizemos uma improvisação com todo o material que levantamos, além de alguns objetos concretos que sugeri que cada um trouxesse para o encontro. Com as ilustrações do Papa de Bacon abertas no solo, cada um buscou reproduzir, criar, compor esse quadro individualmente. A partir do que foi surgindo, especialmente uma figura grotesca trazida por uma das atrizes, indiquei que os outros fossem

5 Fonte: https://en.wikipedia.org/wiki/Study after Vel\%C3\%A1zquez\%27s Portrait of Pope Innoce $\underline{\text { nt_X }}$ 
compondo ao redor dela, buscando uma única imagem refazendo o quadro. Seguiu-se um período de experimentação e improvisação livre, com atmosferas surgidas e instauradas a partir do quadro, que variavam entre sacra e grotesca. As sete pessoas estavam mergulhadas no jogo, e foram introduzindo vozes, falas, textos, músicas, instrumentos (acordeom e pandeiro), cordas e bastões. Esses elementos eram resignificados e utilizados a serviço do jogo. Importante ressaltar que estávamos bastante influenciados e incomodados com a situação política no Brasil daquele momento. Surgiam palavras que serviam como dispositivos estimuladores de potenciais dramatúrgicos, como "ouro", "cristo sexy", “cochigrossi", "brasilianiestúpidi”, "iluditi”, (muita coisa num tipo de italiano e latim), "transamazônica; transa", "pré-sal”, "deus ajuda quem cedo madruga", "samba", "trabalha!!", etc. Foi interessante notar as diferentes modulações de silêncio, música, jogo em grupo e momentos individuais. Surgiram figuras que remetiam a Bacon, evidenciando que os atores traziam referências daquele repertório trabalhado previamente, imagens que constituíam um espetáculo! Imagens de caravelas, da chegada ao Brasil, do escambo com os índios, navio negreiro, ritual antropofágico, remos, trio elétrico, revolução industrial com movimentos repetitivos, "lá vem o Brasil descendo a ladeira", “vem pra Caixa você também”, canto lírico, Macunaíma, petróleo. Depois desse experimento trouxemos outros textos relacionados aos temas que ali apareceram.

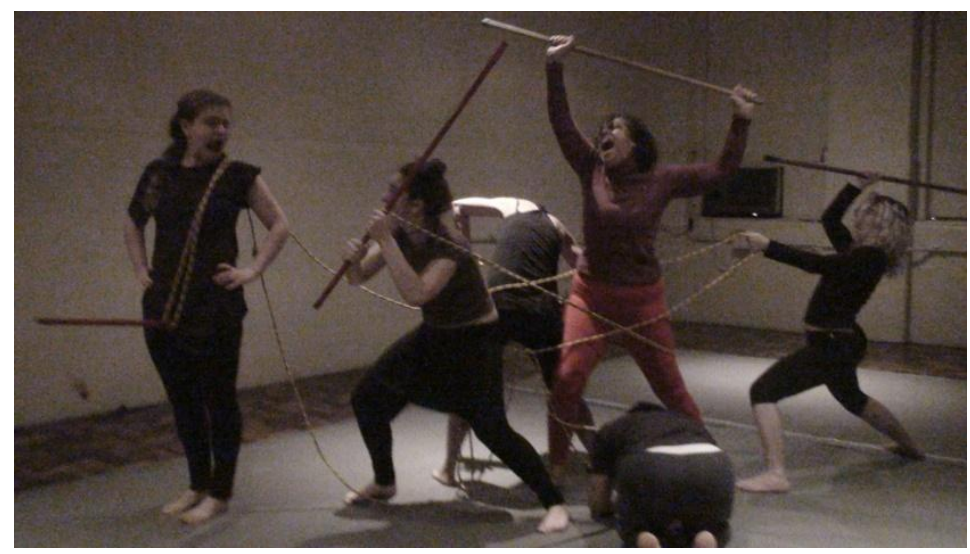

Figura 2: registro de trabalho, $2017^{6}$

\footnotetext{
${ }^{6}$ Fonte: acervo pessoal de Cláudia Sachs
} 
Este experimento reforçou a força dessa pedagogia, pois era evidente o quanto cada um tinha autonomia e liberdade para se mover e compor com o grupo, com diferentes qualidades corporais, presença, disponibilidade, precisão e riqueza imagética. A qualidade psicofísica dos atores vem acompanhada de estratégias dramatúrgicas, uma vez que nossas práticas anteriores haviam utilizado elementos como o looping, a repetição, a continuidade do movimento, a composição no espaço, ou seja, a percepção de onde e como se colocar em relação ao colega, ao grupo, ao espaço. Trata-se de uma construção coletiva a partir do próprio corpo e do olhar que assiste, apreende e constrói.

O objetivo final dessa proposta de trabalho é que se possa pintar o que se queira com o corpo, seja uma pintura que um diretor queria usar como parâmetro ou algo que decidimos usar internamente para nos guiar. Por exemplo, se vou fazer uma personagem de Lorca, posso associar a ele determinadas cores, matérias, dinâmicas, animais, poesia, música, enfim, uma gama de possibilidades imaginativas que se abrem para contribuir com a criação.

Percebe-se assim a influência do alargamento da imaginação, que veio sendo trabalhada nas improvisações a partir das identificações com a natureza das coisas e suas dinâmicas, instrumentalizando o corpo no sentido de alargar suas possibilidades de ritmos, qualidades de presença, percepção de composição no espaço. É com esse corpo previamente trabalhado que o ator vai formar, vai criar uma linguagem. Esse conjunto de práticas corporais, portanto, visa justamente chegar a esse momento de criação com o corpo disponível, com meios concretos, físicos, materializados, incorporados, com a imaginação desperta fluindo através de movimentos corporais de cunho poético.

$$
* * *
$$




\section{REFERÊNCIAS}

DANTAS, Mônica. Dança: o enigma do movimento. Porto Alegre: Ed.Universidade,/UFRGS, 1999.

FREIXE, Guy. La Filiation Copeau, Lecoq, Mnouchkine.Paris: L'entretemps, 2014.

LORELLE, Yves. Dullin-Barrault. L'éducationdramatique en mouvement. Éd. del'Amendier: Paris, 2007.

LECOQ, Jacques. Le corps poétique. Un enseigment de la créacion théâtrale.Paris:ActesSud-Papiers/ANRT, 1997.

NUNES, Sandra Meyer. As metáforas do corpo em cena. São Paulo: Annablume, 2009.

SACHS, Cláudia Müller. A metodologia de Jacques Lecoq. Estudo conceitual.Dissertação (Mestrado em Teatro) - Centro de Artes Universidade Estadualde Santa Catarina-UDESC. Florianópolis, 2004.

SACHS, Cláudia Müller. A Imaginação é um músculo. A contribuição de Lecoq para o trabalho do Ator. Tese (Doutorado em Teatro) - Centro de Artes - Universidade Estadual de Santa Catarina-UDESC. Florianópolis, 2013.

Recebido em março de 2019.

Aprovado em abril de 2019. Publicado em junho de 2019. 